\title{
PROTECTIVE EFFECTS OF Xylopia aethiopica FRUIT ETHANOL EXTRACT ON CADMIUM-INDUCED INFLAMMATION AND DYSLIPIDEMIA IN MALE ALBINO RATS
}

\section{Peter Folorunsho Ayodele*1, Dorcas Ibukun Akinloye, ${ }^{1}$ Adio Jaimiu Akamo, ${ }^{1}$ David Adejare Agboola ${ }^{2}$ and Oluseyi Adeboye Akinloye ${ }^{1}$}

${ }^{1}$ Department of Biochemistry, College of Biosciences, Federal University of Agriculture, Abeokuta, Ogun State, Nigeria

${ }^{2}$ Department of Pure and Applied Botany, College of Biosciences, Federal University of Agriculture, Abeokuta, Ogun State, Nigeria.

${ }^{*}$ Corresponding Author Address: Department of Biochemistry, College of Biosciences, Federal University of Agriculture, Abeokuta, Ogun State, Nigeria.

Email: ayodele.peter@pg.funaab.edu.ng

\begin{abstract}
The wide use of cadmium (Cd) in industry causes great environmental health problems to humans and animals. The aim of this study was to investigate the protective effects of Xylopia aethiopica fruit ethanol extract (XAFEE) on cadmium-induced inflammation and dyslipidemia in male albino rats. Thirty albino rats weighing $120-180 \mathrm{~g}$ were randomly selected into six groups $(n=5)$ : control rats (administered distilled water only), Cd alone group (10 mg/ kg bw), Cd + $150 \mathrm{mg} / \mathrm{kgbw}$ XAFEE, Cd + $300 \mathrm{mg} / \mathrm{kgbw}$ XAFEE, 150 $\mathrm{mg} / \mathrm{kgbw}$ XAFEE and $300 \mathrm{mg} / \mathrm{kgbw}$ XAFEE groups after 2-week acclimatization. The experiment lasted for 21 days, after which blood sample was collected by cardiac puncture. Changes in tumor necrosis factor (TNF- a ), interleukin 10 (IL-10), total cholesterol (TC), triacylglycerol (TAG), phospholipids and free fatty acids (FFAs) concentrations in serum were determined. The results of the present study indicated that $\mathrm{Cd}$ exposure remarkably increased $(p<0.05)$ the TC, TAG, phospholipids, FFAs and TNF- $\alpha$ concentrations, and significantly decreased IL-10 concentration $(p<0.05)$. These findings suggest that inflammatory changes and alterations in lipid metabolism might be one of the mechanisms underlying the subtle effects of Cd toxicity, "dyslipidemia." XAFEE expressed protective role against toxic influence of $\mathrm{Cd}$ on affected parameters in rats. The results raised the possibility of Xylopia aethiopica fruit being considered as a condiment in soup, local drinks, supplements or herbs preparations in areas where there are chances of $\mathrm{Cd}$ exposure, occupationally or environmentally.
\end{abstract}

Key words: Medicinal plant, spices, condiment, anti-dyslipidemic effect and Cd toxicity.

\section{Introduction}

Cadmium, $\mathrm{Cd}$ is one of the most toxic heavy metals present in the environment, and causes serious environmental and occupational hazards to humans ${ }^{[1,2]}$, with a wide range of organ toxicity and long elimination half-life $\quad(10-35 \quad$ years $)$. Environmental contamination by cadmium results from its industrial use and its presence in agricultural fertilizers. Non-occupational exposure to cadmium in humans predominantly results from smoking, air pollution, and consumption of cadmium-contaminated sea foods and water ${ }^{[3]}$. Cadmium is implicated in the pathogenesis of several diseases, including cardiovascular disease (CVD) which may ensue from 
metabolic disorders such as diabetes and dyslipidemia ${ }^{[4]}$. The available conventional drugs used as antidyslipidemic agents are expensive and have adverse effects [5].

Xylopia aethiopica or Ethiopian pepper belongs to the family "Annonaceae" and is among the species that thrive in the evergreen rain forests of tropical and subtropical Africa [6]. It has its English name as Negro pepper or grains of Selim. In Nigeria, Yoruba call it 'Eeru', Igbo call it 'Uda' and Hausa call it 'Chimba' [6]. This plant possesses great nutritional and medicinal values in African traditional medicine for several centuries owing to its wide array of therapeutic indications in the treatment of cough, bronchitis, malaria among other diseases ${ }^{[7]}$.

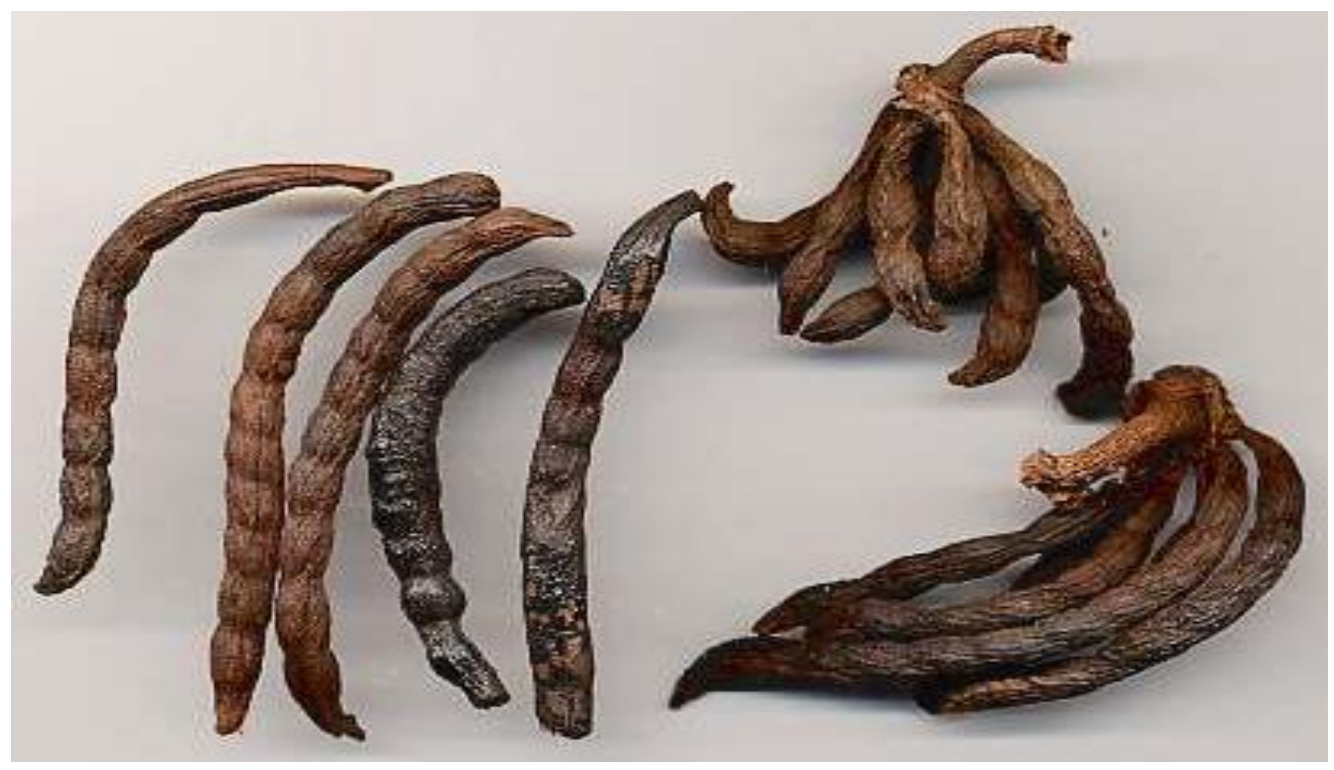

Figure. 1: Snapshot of Xylopia aethiopica fruit

In both human and animal studies, it has been shown that Cd perturbs cholesterol, triacylglycerol (TAG) and lipoproteins metabolism ${ }^{[7,8,9]}$. Oxidative stress and inflammatory changes have been proposed as one of the numerous mechanisms in the pathogenesis of Cd toxicity, e.g. dyslipidemia, diabetes mellitus and cancer amongst others ${ }^{[10]}$.

Nevertheless, several studies have investigated how various medicinal plants and spices containing natural anti-oxidants exert anti-inflammatory and anti-dyslipidemic effects, which subsequently prevents the damaging consequences of inflammation and dyslipidemia [11,12]. Thus, the present study 
was designed to evaluate the anti-inflammatory and anti-dyslipidemic effects of Xylopia aethiopica fruit ethanol extract (XAFEE) against cadmium-induced inflammation and dyslipidemia in male albino rats.

\section{Materials and methods}

\subsection{Chemicals and reagents}

Cadmium chloride and chemicals used for this study was bought from Bridge Biotech. Ilorin, Kwara state. Kits were purchased from Elabscience ${ }^{R}$ Biotechnology Co. LTD, USA. Other chemicals were of analytical grade.

2.2 Collection and identification of plant material (fruit)

Dried fruit of Xylopia aethiopica were purchased from a local herb store, Osiele, Abeokuta, Ogun State, Nigeria. Its botanical identification and authentication (FUNAAB H-0061) was done by a Botanist in the Department of Pure and Applied Botany, College of Biosciences, Federal University of Agriculture, Abeokuta, Ogun State, Nigeria. The fruit were washed with clean tap water and allowed to dry again.

\subsection{Extraction of plant material (fruit)}

The dried fruit of Xylopia aethiopica were pulverized in a clean dry mortar. Six hundred grams $(600 \mathrm{~g})$ of the pulverized sample was cold macerated in $6.0 \mathrm{~L}$ of absolute ethanol $(1: 10 \mathrm{w} / \mathrm{v})$ over $48 \mathrm{~h}$ periods. The extract was filtered using clean Whatmann No.1 filter paper, pore size of 100 (195 mm by $195 \mathrm{~mm}$ ). The filtrate was concentrated using rotatory evaporator, and placed on water bath to allow evaporation of the solvent.

\subsection{Determination of median lethality dose, $\mathrm{LD}_{50}$}

The $L_{50}$ of the XAFEE was tested on sixteen (16) albino rats using the modified method and calculation proposed by Lorke [13]. Different doses on single administration of XAFEE were administered orally to the rats in four groups $(n=4)$. Each group received $1000 \mathrm{mg} / \mathrm{kg} \mathrm{b.w,} 2000 \mathrm{mg} / \mathrm{kg}$ b.w, 3000 $\mathrm{mg} / \mathrm{kg} \mathrm{b.w} \mathrm{and} 4000 \mathrm{mg} / \mathrm{kg}$ b.w respectively. The rats were monitored and examined for $24 \mathrm{hrs}$ for any 
sign of toxicity and mortality after the XAFEE administrations. Maximum dose with $0 \%$ and minimum dose with $100 \%$ mortality were recorded, and used to determine the $\mathbf{L D}_{50}$ of the XAFEE as follows:

$L D_{50}=\sqrt{ } a \times b$

Where $a=$ Maximum dose with $0 \%$ mortality $b=$ Minimum dose with $100 \%$ mortality.

Ten (10 \%) of the LD 50 was used for therapeutic doses selection.

\subsection{Experimental rats}

The approval of the departmental animal ethical committee (FUNAAB- BCH) was taken prior the experiment with ethical number: FUNAAB- BCH- APF0441, dated 20th November, 2019. All the protocols and the experiments were conducted in strict compliance according to the guidelines approved by the committee.

Thirty (30) male albino rats weighing $120-180 \mathrm{~g}$ were purchased from College of Veterinary Medicine, FUNAAB, and randomly distributed into six $(6)$ groups $(n=5)$. The rats were fed ad libitum, kept on a $12 \mathrm{~h}$ light-dark cycle periods and acclimatized for two weeks prior the experiment, which lasted for a period of 21 days.

Table 1: Experimental design

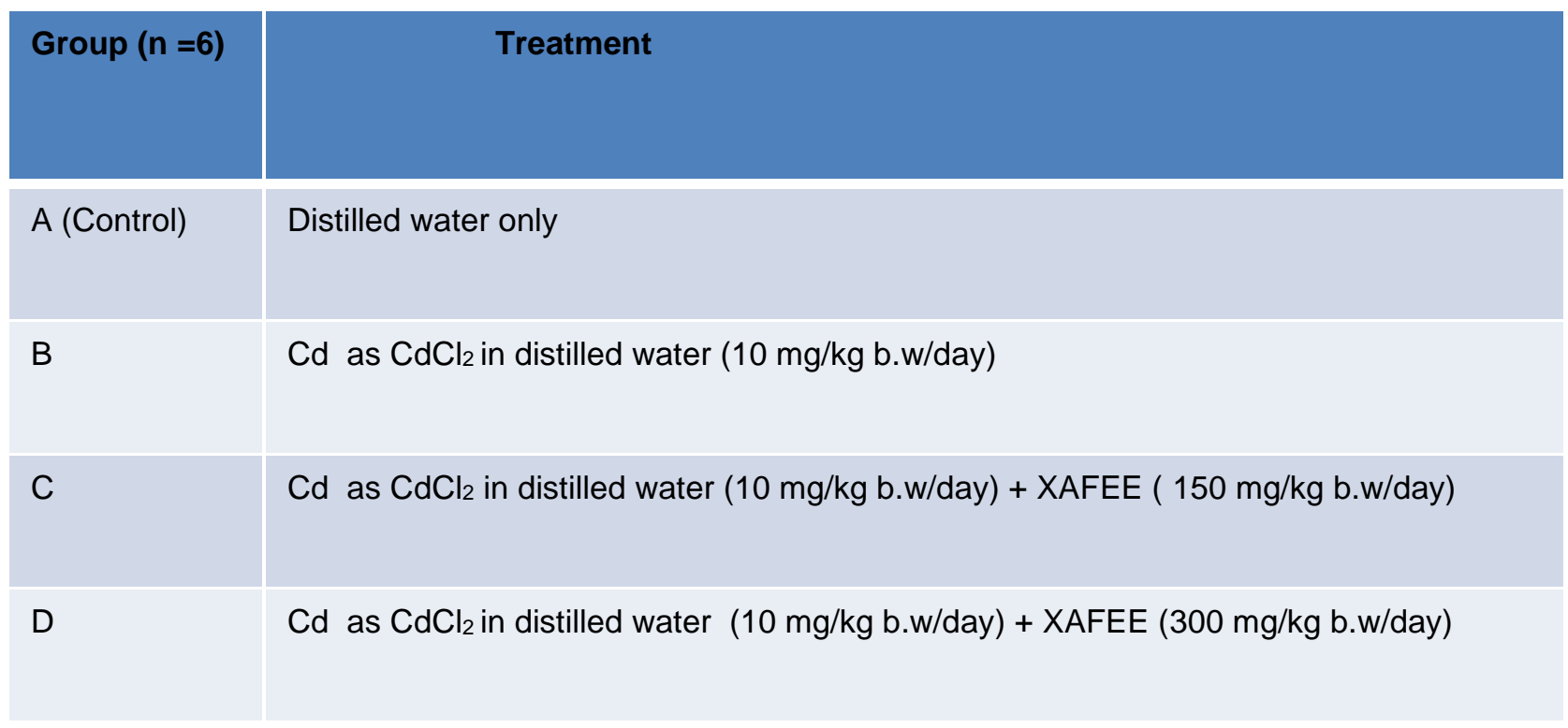




\begin{tabular}{|l|l}
\hline $\mathrm{E}$ & XAFEE (150 $\mathrm{mg} / \mathrm{kg} \mathrm{b.w} /$ day $)$ \\
\hline $\mathrm{F}$ & XAFEE (300 $\mathrm{mg} / \mathrm{kg} \mathrm{b.w} /$ day $)$
\end{tabular}

\subsection{Sacrifice}

The oral route was selected because it depicts more reasonably how the general human population is exposed to cadmium. After 21 days of the experiment, the rats were fasted overnight and sacrificed under light diethylether anaesthesia.

\subsection{Serum biochemical estimation}

Blood sample was collected via cardiac puncture into plain tubes and allowed to stand for about 30 mins. Thereafter, centrifuged at $3000 \mathrm{rpm}$ for 10 mins to obtain serum and processed for biochemical analysis.

2.8. Determination of inflammatory biomarkers

TNF- $\alpha$ and IL-10 levels were determined using Sandwich - enzyme-linked immunosorbent assay (ELISA) method.

\subsection{Determination of lipid profile biomarkers}

\subsubsection{Determination of total cholesterol concentration}

Total cholesterol concentration was determined spectrophotometrically according to the method described by Allain et al. [14]. The method involves the use of three enzymes; cholesterol esterase, cholesterol oxidase and peroxidase. In the presence of the enzymes, the mixture of N-ethyl-N-propyl-Manisidine (ADPS) and 4-aminoantippyrine (4-AA) are condensed by hydrogen peroxide to form quinoneimine dye, which is proportional to the concentration of cholesterol in the sample.

\subsubsection{Determination of triacylglycerol concentration}


Triacylglycerol concentration was determined spectrophotometrically according to the method described by Buccolo and David [15]. This method is based on the enzymatic hydrolysis of triglyceride to glycerol and free fatty acids by Lipoprotein lipase. The glycerol was phosphorylated by adenosine triphosphate in the presence of glycerokinase to form glycerol-3-phosphate and adenosine diphosphate.

\subsubsection{Determination of phospholipids concentration}

Phospholipids concentration was determined spectrophotometrically according to the method described by Stewart [16]. Phospholipids are hydrolyzed by phospholipase D and the liberated choline is subsequently oxidized by choline oxidase to betaine with the simultaneous production of hydrogen peroxide. In the presence of peroxidase, the hydrogen peroxide couples oxidatively with 4aminophenazone and dichlorophenol to form a quinonemine dye.

\subsubsection{Determination of free fatty acids concentration}

Concentration of free fatty acids was determined according to the method described by Brunk and Swanson, [17].

\subsection{Data Analysis}

All values were expressed as the mean \pm standard error of mean (SEM). The data were analyzed using one-way analysis of variance (ANOVA) and significant means were separated by post hoc Duncan's multiple range test at $p<0.05$.

\section{Results}




\section{Inflammation biomarkers in serum}

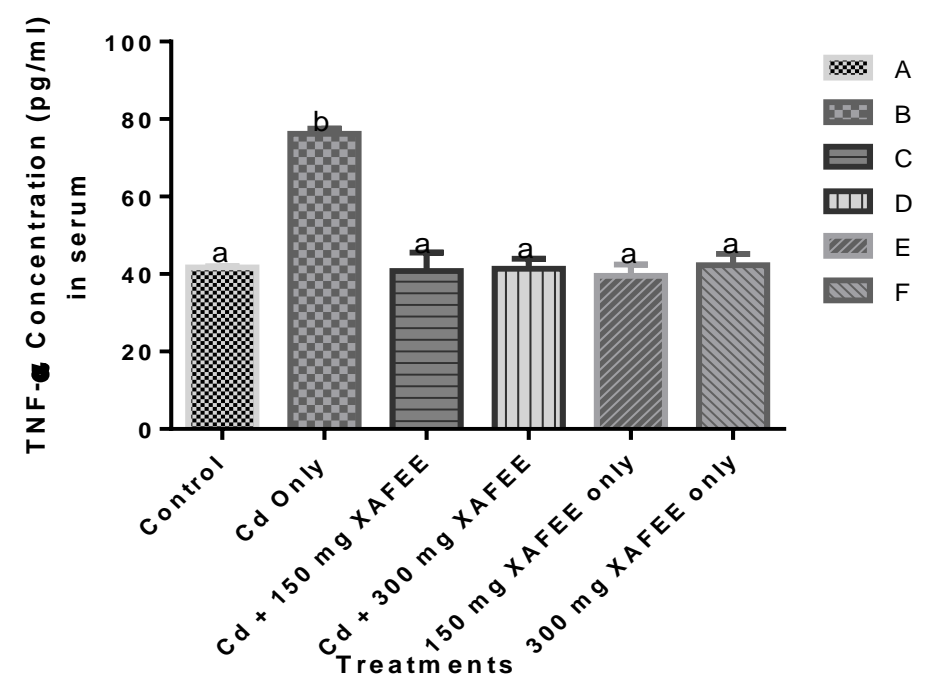

Figure 2: Effects of Cd and XAFEE on TNF- $\alpha$ concentration

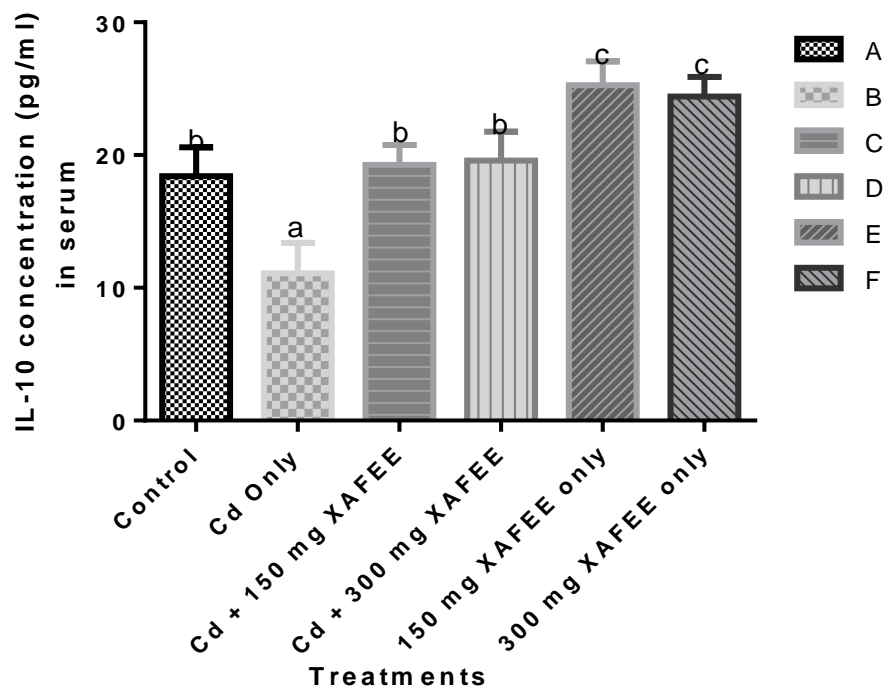

Figure 3: Effects of Cd and XAFEE on IL- 10 concentration 
Figures 2 and 3 showed the effects of $\mathrm{Cd}$ and XAFEE on inflammation biomarkers in serum. The group exposed to Cd only showed a significant increase $(p<0.05)$ in TNF- $\alpha$ concentration and a remarkable decrease in that of IL-10 compared to negative control in both figures respectively. Treatment with XAFEE remarkably reversed the concentrations of these TNF- $\alpha$ and IL-10 towards control level, in both figures respectively.

\section{Lipids profile assay in serum}

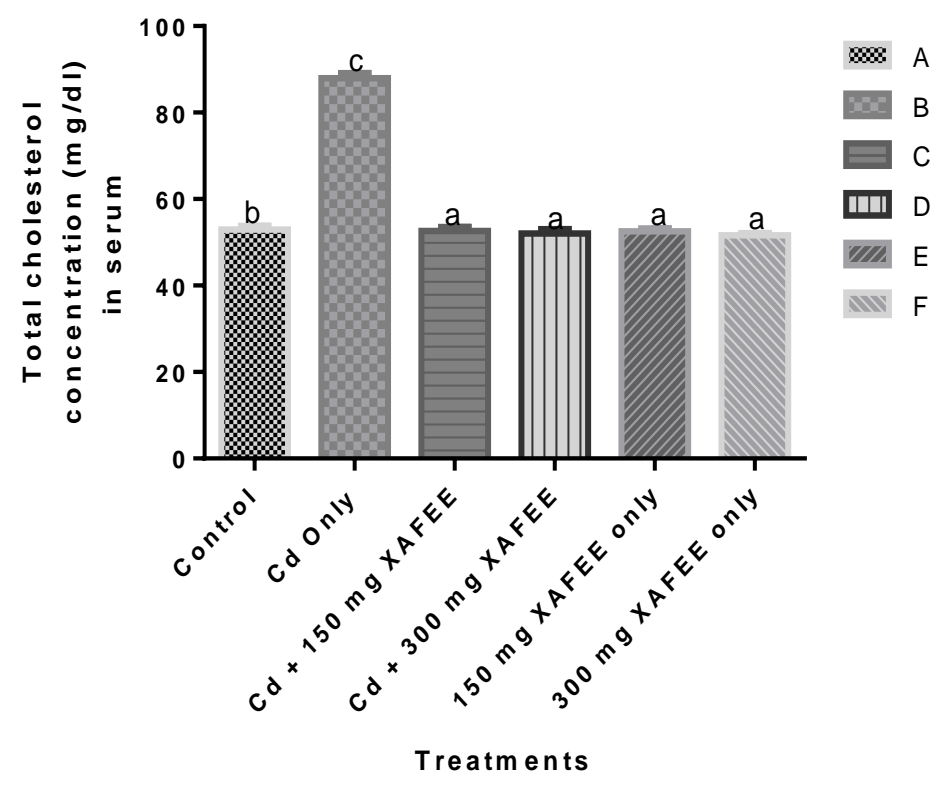

Figure 4: Effects of Cd and XAFEE on total cholesterol concentration

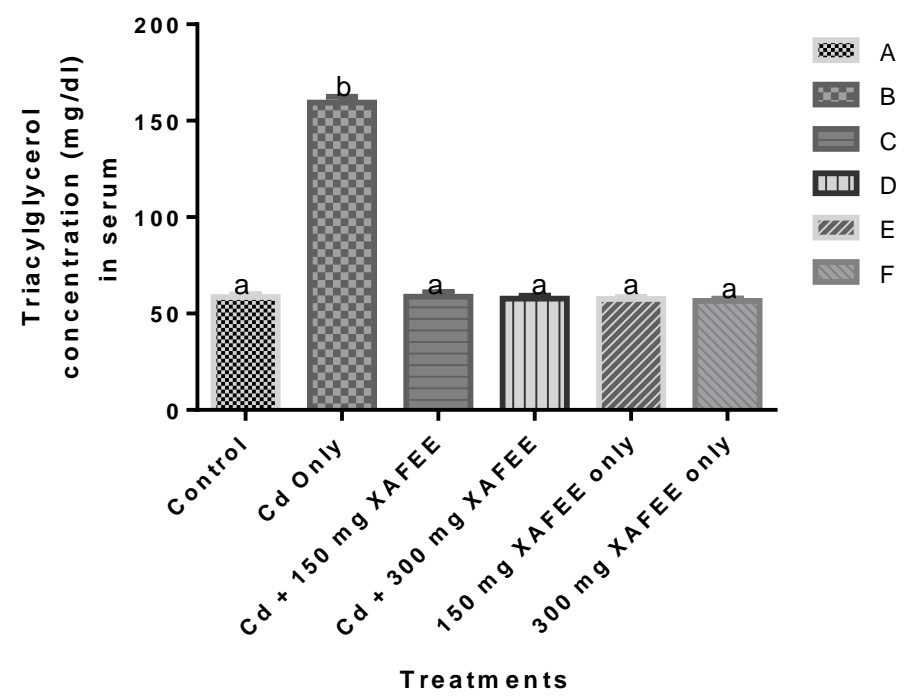

Figure 5: Effects of Cd and XAFEE on triacylglycerol concentration 


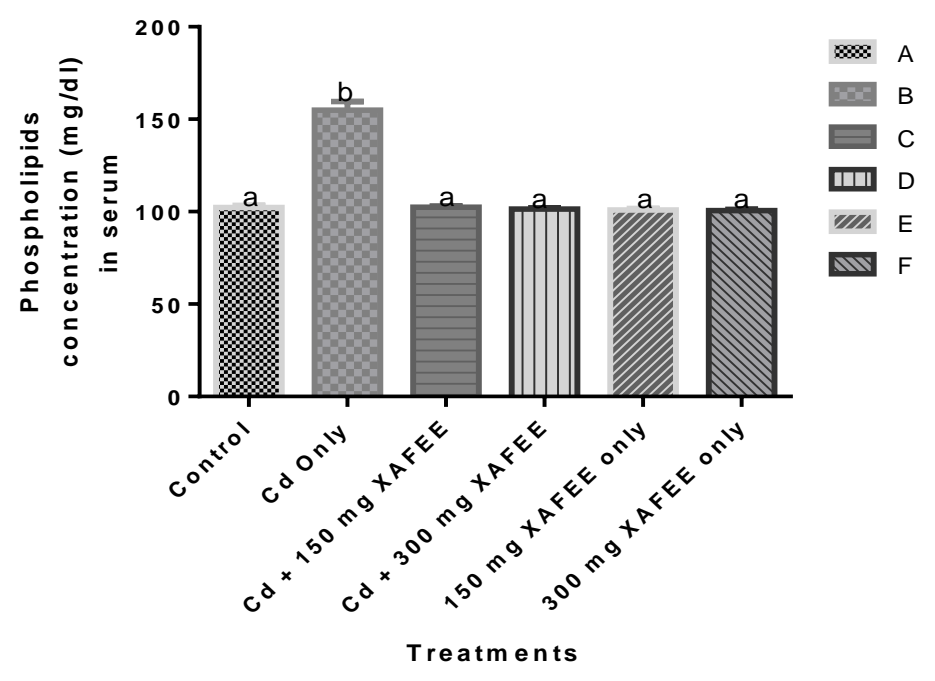

Figure 6: Effects of Cd and XAFEE on phospholipids concentration

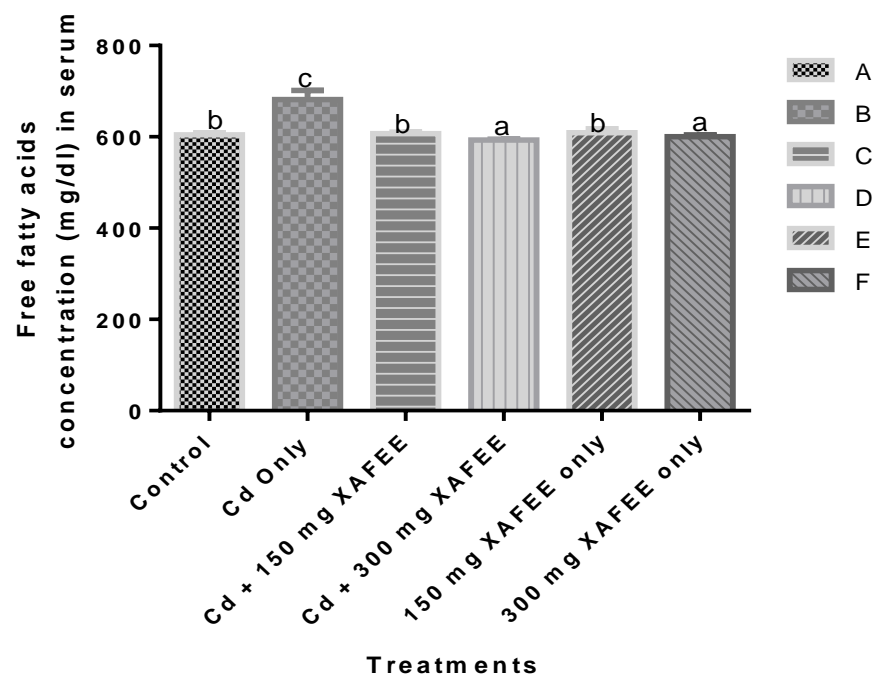

Figure 7: Effects of Cd and XAFEE on free fatty acids concentration

Figure 4-7 showed the effects of Cd and XAFEE on lipid profile in serum. The group exposed to Cd only showed a remarkable increase in the concentrations of these lipids. Treatment with XAFEE normalized this perturbation towards the negative control level. 


\section{Discussion}

Cadmium (Cd) is a toxic metal that is widely used in different industries. Exposure to Cd causes damage to various organs including liver, kidneys, lungs, bones, testes and placenta depending on the dose, route of administration and duration of exposure [18]. It promotes an early oxidative stress and afterward contributes to the development of serious pathological conditions, because of its long retention in some tissues ${ }^{[19]}$. The present results have clearly shown the ability of $\mathrm{Cd}$ to induce oxidative stress and inflammatory changes in the blood.

The remarkable increase in TNF- $\alpha$ (Figure 2) and decrease in IL-10 (Figure 3) concentrations caused a pathological event known as inflammation. Inflammation is a series of defense mechanism associated with the release of pro-inflammatory cytokine, alongside with swollenness, redness, hardness, heat and pain in tissues. However, Cd promotes an early oxidative stress and afterward contributes to the development of inflammation and serious pathological conditions like dyslipidemia and other metabolic disorders, because of its long retention in tissues [20].

The ability of XAFEE to reverse these markers might be due to the anti-inflammatory property of the Xylopia aethiopica fruit, revealing that the fruit contains 9-octadecenoic acid and $\mathrm{n}$-hexahecanoic acid which have been reported to have anti-inflammatory potentials [21].

Changes in the distribution of lipids after Cd exposure is associated with a change in the turnover of lipids in medium of high oxidative stress which is known to modify the properties of membranes. Increased concentration of phospholipids in serum may lead to the formation of numerous multi-lamella inclusion bodies in cell, causing a loss of cell functions which compromise the cell integrity, thereby promoting cellular dysfunction [22]. The observations in Figure 4-7 established the fact that Cd causes alteration in lipid metabolism following production of free radicals and oxidative damage caused by $\mathrm{Cd}$, which plays an important role in the metabolic reactions of the animals. These findings correlate with the studies reported on the contribution of oxidative stress to the modification of lipids which is associated with oxygen free radical production, resulting in oxidative deterioration of lipids ${ }^{[23] . ~ I n ~ t h e ~ c u r r e n t ~ s t u d y, ~}$ considerable increases in TC, TAG, phospholipids and FFAs were observed in rats exposed to Cd alone 
as compared with the control group. Other studies have demonstrated similar increases after administration of $\mathrm{Cd}$ to rats ${ }^{[24]}$. In the study, Xylopia aethiopica fruit ethanol extract exerted antihyperlipidemic effects.This might be due to the anti-oxidative and ant-dyslipidemic properties of the Xylopia aethiopica fruit, enabling it to normalize the lipids levels ${ }^{[25,26] .}$

\section{Conclusion}

The results raised the possibility of Xylopia aethiopica fruit as a good treatment agent for inflammation and dyslipidemia. However, further study could be done on the bioactive components responsible for the anti-inflammatory and anti-dyslipidemic properties of the fruit.

\section{Aknowlegement}

We appreciate all participants, including the laboratory technologists who jointly worked with us towards the success of this work, but couldn't be listed in the authors list.

\section{Authors contribution}

All authors contributed equally towards this research.

\section{Conflict of interest}

All authors declared no conflict of interest.

\section{REFERENCES}

1.Tarasub, N.; Devakul, N.; Ayutthaya, W. Effect of curcumin on cadmium-induced hepatotoxicity in rats. Thai J Toxicol. 2008, 23(2): 100-107.

2. Ajilore, B.S.; Olugbenga A. Hepatoprotective potentials of methanolic extract of the leaf of Momordica charantia linn on cadmium -induced hepatotoxicity in rats. JNSR. 2012, 2 (7): 41-47.

3. Jarup, L. Hazards of heavy metals contamination. Br. Med. Bull. 2003, 68: 167-182. 
4. Zhang, W.; Fievez, L.; Cheu, E.; Bureau, F.; Rong, W. Anti-inflammatory effects of formoterol and ipratropium bromide against acute cadmium-induced pulmonary inflammation in rats. Eur. J. Pharmacol. 2010, 628: 171-178.

5. Hjizadeh, R.M.; Miezani, E. The effects of consumption of raw garlic on serum lipid level and, blood sugar and a number of effective hormones on lipid and sugar metabolism in hyperglycemic and/or hyperlipidemic individuals. $A B C .2011,1$ (2): 29-33.

6. Orwa, C.; Mutua, A.; Kindt, R.; Jamnadass, R.; Simons, A.; Agroforestree Database: A Tree Reference and Selection Guide Version 4.0: 2009.

7. Oloyede, A.M.; Aduramigba-Modupe AO. Antimicrobial activities of crude ethanolic extract of Xylopia $\begin{array}{llllllll}\text { aethiopica. } & \text { Int. } & \text { J. } & \text { Curr. } & \text { Res. } & \text { 2013, } & 3 & \text { (10): }\end{array}$

8. Larregle, E.V.; Varas, S.M.; Olivieros, L.B.; Martinez, L.D.; Anto'n, R., Marchevsky, E.; Gime' nez, M. Lipid metabolism in liver of rat exposed to cadmium. FCT. 2008, 46, 1786-1792.

9. Rogalska, J.; Brzo'ska, M.M.; Roszczenko, A.; Moniuszko-Jakoniuk, J. Enhanced zinc consumption prevents cadmium-induced alterations in lipid metabolism in male rats. IJBCS. 2009,177: 142-152.

10. Prabu, S.M.; Shagirtha, K.; Renugaderi, J. Amelioration of cadmium-induced oxidative stress, impairment in lipids and plasma lipoproteins by the combined treatment with qercetin and tocopherol in rats. J. Food Sci. 2010, 75, T132-T140.

11. Deepa, P.R.; Varalakshmi, P. Atheroprotective effect of exogenous heparin-derivative treatment on the aortic disturbances and lipoprotein oxidation in hypercholesterolemic diet fed rats. Clin. Chim. Acta 2005, 355 (1-2): 119-130.

12. Flora, S.J. Structural, chemical and biological aspects of antioxidants for strategies against metal and metalloid exposure. Oxid Med Cell Longev. 2009, 2: 191-206. 
13. Hadi, N.; Yousif, N.G.; Al-Amran, F.G.; Huntei, N.K.; Mohammad, B.I.; Ali, S.J. Vitamin E and telmisartan attenuates doxorubicin induced cardiac injury in rat through down regulation of inflammatory response. BMC. 201212, (1): 63.

14. Lorke, D. Arch. Toxicol.1983, 55: 275-287.

15. Allain, C.C.; Poon, L.S.; Ckau, C.S.G.; Richmond, W.; Fu, P.D. Clinical Chemi. 1974, 20: 470-478.

16. Buccolo, G.; David, H. Quantitative determination of serum triacylglycerols bythe use of enzymes. Clin. Chem. 1973,19: 476-482.

17. Stewart, J.C.M. Colorimetric determination of phospholipids with ammonium ferrothiocyanate. Anal. Biochem. 1979,104 (1): 10-14.

18. Brunk, S.D.; Swanson, J.R. Colorimetric method of free fatty acids in serum validated by comparison with gas chromatography. Clin. Chem. 1981, 27 (6): 924-926.

19. Pari, L.; Murugavel, P. Diallyl tetrasulfide improves cadmium induced alterations of acetylcholinesterase, ATPases and oxidative stress in brain of rats. J. Toxicol. 2007, 234: 44-50.

20. Bagchi, D.; Bagchi, M.; Stohs, S.J.; Das, D.K.; Ray, S.D.; Kuszynski, C.A.; Joshi, SS.; Pruess, H.G. Free radicals and grape seed proanthocyanidin extract: importance in human health and disease prevention. Toxicology 2000, 148: 187-197.

21. Ekuadzi, E.; Biney, R.P.; Benneh, K.; Jonathan, O.A. Anti-inflammatory properties of betulinic acid and xylopic acid in the carrageenan-induced pleurisy model of lung inflammation in mice. Phtother Res. 2018, $32(3):$ 480-487.

22. Samarghandian, S.; Azimi-Nezhad, M.; Samini, F. Ameliorative effect of saffron aqueous extract on hyperglycemia, hyperlipidemia, and oxidative stress on diabetic encephalopathy in streptozotocin induced experimental diabetes mellitus. Biomed Res. Int. 2014, 9: 208-257. 
23. Samarghandian, S.; Azimi-Nezhad, M.; Afshari, R.; Farkhondeh, T.; Karimnezhad, F. Effects of buprenorphine on balance of oxidant/antioxidant system in the different ages of male rat liver. J Biochem Mol Toxicol. 2015 b, 29: 249-253.

24. Pathak, N.; Khandelwal, S. Role of oxidative stress and apoptosis in cadmium induced thymic atrophy and splenomegaly in mice. Toxicol. Lett. 2007, 169: 95-108.

25. Adefegha, S.; Oboh, G. Effect of diets supplemented with Ethiopian pepper [Xylopia aethiopica (Dun.) A. Rich (Annonaceae)] and Ashanti pepper [Piper guineense Schumach. Thonn (Piperaceae)] on some biochemical parameters in normal rats. Asian Pac. J.Trop. Biomed. 2012,2 (2): S558-S566.

26. Moukette, M.B.; Pieme, C.A.; Nya-Biapa, P.C.; Ngogang, J.Y. In-vitro antioxidant and antilipoperoxidative activities of bark extracts of Xylopia aethiopica against ion mediated toxicity on liver homogenates. JCIM. 2015, 12 (3): 195-204. 